\section{Phenylbrenztraubensäure im Urin}

W. G. Guder

München, Deutschland

Synonym(e) Phenylketone im Urin
Englischer Begriff phenylketonuria; phenylalanine in urine

Definition Erhöhte Ausscheidung von Abbauprodukten des Phenylalaninkatabolismus mit Phenylpyruvat, -laktat, -acetat. Nicht mehr angewendet $>$ Phenylalanin im Urin. 